\title{
Towards the Development
}

\section{of a Library Management} Information System

This paper outlines an approach, with both widespread implications and specific practical steps, for assembling some of the data that library administrators now require in order to make libraries operate more effectively. These data have not been assembled in the past because the costs in staff time alone have been and continue to be prohibitive for most institutions.

One major impediment to effective library administration is the lack of a comprehensive management information system (MIS). Some investigators in this area seem to have become fascinated with the potential value of various elusive and fugitive library statistical measures, but they have given little attention to the operational systems that would be required to assemble these data. The proposal outlined here stresses the need for a total systems approach, based upon standardized terminology, machine-aided data collection, and customized computer processing and reporting as well as systematic training and documentation.

After the proposed MIS is developed, it can be offered to subscriber libraries by a bibliographic utility or network system at variable rates determined by input data volume, processing times, and output report requirements.

\section{INTRODUCTION}

One of the persistent problems in academic library planning and decision making is obtaining an accurate picture of exactly what is going on within the library. We are used to keeping counts of our operations, but we are seldom comfortable with the accuracy, timeliness, or completeness of this data once assembled. All libraries have some kind of statistical data system, but I would venture to say that in few libraries is the system considered adequate. Some reasons for this unfortunate situation are presented in this paper along with a general outline of an improved system and the steps that may be necessary for its realization.

\section{THE NEED}

Investigators have repeatedly decried the lack of needed data to conduct research in

Robert S. Runyon is director, University Library, University of Nebraska at Omaha. library operations. ${ }^{1,2}$ Doubtless the problem exists in many areas, but there are signs that we now have the knowledge and the tools required, and that it may be an appropriate time for the initiation of specific projects within certain organizations to address the overall need. That need was concisely summarized by Urquhart in a paper that was suitably addressed primarily to service considerations:

Nowadays we must recognize the need to quantify the problems of librarianship so that management can plan their policies on a rational basis. There is a particular need to develop measurement techniques which can be used to describe library processes, and provide management with up-to-date information. Such techniques must operate within three restraints:

they must be inexpensive to operate;

they must not interfere with existing services; they must provide reproducible results. ${ }^{3}$

One hopeful sign is the growing professional interest and publication in the area of 
library measurement and evaluation. Fifteen years ago this kind of work was being done on the outside, and confined typically to university operations research departments. Now it is beginning to form a widening stream in our professional literature, and as indicated by the 1980 ALA Preconference on Library Effectiveness, much of the quantitative work is now being done within the profession by library practitioners and library school faculty members. ${ }^{4}$

Whereas a few years ago, the requirements and processes for generating library statistical data were largely external to the library, the situation has begun to shift. Now there is both a high degree of need and matching technical capability for developing sophisticated statistical records within each academic library. This is not to say that individual librarians will now become operations research experts, but that through the marriage of newer conceptual developments in library measurement and computer processing we can now accomplish that which could not be done before. This will become clearer as we examine long-standing obstacles to statistical record keeping. But first we need to outline a conceptual model for library data to support administrative decision making.

\section{A Conceptual Model}

In most statistics committee discussions and in the published literature, we continue to speak of library measurement in terms of isolated tallies of individual items and events occurring within a library. Our thinking has remained fixed on the relatively narrow issue of how to define and report several limited categories of measurement. In addition, those categories of data, collected for purposes of local operational control and national reporting, tend to have very little relationship to those which are called for or utilized in empirical research studies. The reason for this lies in the absence of a broad conceptual model of library data that can be used in the development of a detailed statistical data system applicable to a wide range of operational planning, reporting, and research purposes.

The models which need to be constructed include both verbal and graphic descriptive and explanatory models as well as mathematical and statistical models. It would be as serious a mistake to rush into the premature construction of the more precise quantitative models as it would be to avoid quantification when it becomes possible. In any complex organization where there are many variables which must be considered in the resolution to any problem, it is necessary to become specific and quantitative about the factors which must be changed. ${ }^{5}$

In order to develop such models we must turn our attention to the key decision-making issues about and within the library. Our question must be, "What data is needed in order to derive more timely, reliable, and far-reaching decisions?" Doubtless there are also other decision-making criteria that should be considered, and those might be best addressed within a special task force of library administrators representing a sampling of major library organizational types. Numerous writers have pointed out the necessity for administrators to be involved at the outset in the establishment of goals and objectives for the development of an MIS. ${ }^{8}$ Unfortunately, this critical and most difficult first step is frequently overlooked or delayed beyond the point at which the system design has become frozen in its basic data structure and organization.

The conceptual model that seems to be required here is a set of integrated, decisionrelated data categories appropriate to the overall administration of a library. An abbreviated example of such a data set for an academic library is outlined in appendix A. This illustrative example is suggested as a monthly planning report to senior-level administrators. Other more or less detailed reports might be useful at other intervals for different purposes.

For an MIS to be detailed in coverage and broad in application, it is imperative that the data categories be precise and well defined. Fortunately, the process of developing many of the fundamental terms, definitions, and relationships has been effectively begun in the work done so far on the National Center for Educational Statistics (NCES) Handbook of Standard Terminology for Recording and Reporting Information about Libraries. The long and complicated history of this important document is summarized in the 1980 Bowker Annual. ${ }^{7}$ The introduction to the Handbook points to the required expansion 
of our vision from microscopic counting activities to overall management and decisionmaking concerns:

This Handbook describes basic management information useful in academic, public, school, and special libraries. An underlying premise of the Handbook is that all types of libraries have a common set of functions, purposes, and resources which outweigh the differences in setting, size, or organizational goals. The data base is built upon a common set of terms related to those common functions, purposes, and resources, while accommodating and providing for those terms unique to each type of library. ${ }^{8}$

As indicated above, it should now be possible to proceed towards the development of a generalized MIS that addresses the needs of academic, public, special, school, and other types of libraries. The examples and allusions in this paper are drawn largely from the academic library scene, but that simply represents this writer's experience and bias. Other related and compatible examples (in terms of an integrated, multitype library MIS) could be offered to illustrate the application to other types of libraries.

One benefit of an overall conceptual model is to allow a detailed specification of the data to be collected at the level of individual library operations, which can later be grouped and regrouped into regional and national summaries and profiles. As of yet, we don't have this kind of data-handling capability in libraries, and we are not likely to achieve it until we have thought our decisionmaking needs through in terms of a comprehensive MIS, over and above the need for consistent rules in the counting of minute items and events.

\section{Characteristics OF THE MOdeL}

A number of library investigators have described statistical measures and related interpretations useful in evaluating library performance and effectiveness. ${ }^{\circ}$ During the past several years, there has also been extensive study and effort directed towards the standardization of library statistical terminology. These efforts will be discussed later. What is now needed is the combination of broad management reporting concepts with the detailed technical description of library measurement parameters. Again the NCES Handbook appears to be the most ambitious effort in this direction to date. One of the early NCHEMS reports that led to the development of the Handbook summarized its seven major data categories as follows:

... the data contained in the management information system describes the environment, the overall resources, and the programmatic activities of the library. The environmental data of the library includes information which describes the external setting of the library, the internal organization of the library and the target group served by the library. The overall resources of the library include four major types of data: collection resource data, human resource data, financial data and facility resource data. Finally the data concerning programmatic activities organizes the library into major activity or functional areas. For each of these, a series of measure categories are used to describe and evaluate the activity of the library. These measures describe revenues/expenditures, personnel, facilities, activities, users, and outcomes/performance of each of the activity areas. ${ }^{10}$

Two useful features of the Handbook in its current form are a data classification and hierarchical coding scheme. These, in combination with a glossary of all terms employed, will enable the administrator to specify precisely the type and level of data to collect and report in order to compile a comprehensive, quantitative description of an individual library.

When the re-edited version of the NCES Handbook is ready for field review, librarians should be thinking in the broadest possible terms about uses, permutations, and combinations of the data. Other categories that we have tended to overlook in the past, but which should increasingly occupy our attention, are indexes and output or performance measures. We are familiar with some useful applications of index numbers in reporting publishers' price changes and national economic trends, but it seems possible to conceive of "the construction and use of index numbers"11 also in some areas of library resources and operations. One of these may be the profiling and shorthand description of library collections and user response rates. We already have indexes for retrieval efficiency ${ }^{12}$ and the technical services cost ratio, ${ }^{13}$ but we haven't been able to include these researchoriented measures in a library MIS. Now that we have examples and case histories of the application of MIS in business and university 
environments, ${ }^{14,15}$ it seems feasible with network resources to apply such systems in libraries. In the ALA Preconference on $\mathrm{Li}$ brary Effectiveness, there was an outline of a quite advanced design for an MIS in a public library. ${ }^{16}$ Drawbacks with such localized system developments are that they are costly, and in addition, it is unlikely that they will be compatible for transfer to other library settings.

Cost is a consideration, and the MIS must have a reasonable cost compared to its worth. The economics of information systems requires constant balance between the value of the information carried in the system, and the cost of designing and operating it. ${ }^{17}$

Of course if the development of a generalized MIS is long delayed, it is quite likely and even feasible for a library to develop its own, using some of the NCES Handbook data categories and definitions. Certain flexible and user-oriented software packages, such as MARK IV, SCRIPT, and FOCUS, are now available and can facilitate the writing of the requisite computer programs. Another option is the use of an "electronic worksheet" program such as VISICALC which is now available on many microcomputers.

\section{TERMINOLOGY}

The problem with terminology has impeded the development of a generalized library MIS in the past. It seems now that there is well-grounded hope for progress in this area. Librarians will doubtless settle their terminological confusions and disputes if there are short-term, positive benefits in doing so. One such benefit will be the ready availability of the kind of statistical tabulations and output reports proposed here. Another major incentive to agreement will be the adoption of the new standards for library statistical terminology being considered in $1980-81$ by the American National Standards Institute (ANSI Committee Z39.7).

The committee is working on a draft standard that contains 482 categories of library data. This compares to only 31 items in the Association of Research Libraries annual statistics, and 70 items in the LIBGIS survey form. The ANSI standard is now being developed in coordination with the NCES Handbook revision process. Concerted effort is being applied to assure that measurement terms and their definitions cover a broad range of conventional and potentially innovative measures. Terms must be given precise delineations so there is little question about what item counts are to be included with a category. As an example, the definitions used for government documents and microforms in most current statistical surveys are insufficiently precise. Built into the design of the terminology must be the possibility of combining atomic and molecular terms (and tabulations), either on input or in processing. This is necessary in order to customize data collection forms and output reports to meet the requirements of different types of libraries. For example, it is possible to specify media and microform types in great detail, but for certain users or certain reports, aggregate or generic tabulations may be more useful.

\section{Organizational \\ Considerations}

For years, there have been manifold ALA committees humming with projects directed towards the rationalization of library statistical terminology and concepts. Beyond this, there have been numerous committee efforts to support the definition, collection, analysis, and reporting of specific new measurement categories. One example has been the innovative work of the ALA Committee on Statistics for Reference Services, which produced, under the direction of Katherine Emerson, several new publications, conference programs, and training activities related to the measurement of reference transactions. ${ }^{18}$ Despite the effort of many hard-working people, it took this committee several years of intense work to arrive at acceptable definitions of directional and reference transactions. Additional effort and time was expended in trying to insert these new "standardized" terms into nationally distributed data collection forms. It was a major victory to get the categories incorporated as cells in the LIBGIS reporting forms for academic libraries. After this was done, and the filled-out forms started coming back from the field, it became apparent that librarians were still unclear about the purpose, definition, and relationship of the reporting categories.

The point of all this is not simply to belabor the obvious fact that national committee activities grind exceedingly slow, even when favored with superior leadership and expert 
participation. Rather, it is to suggest that farreaching change in library statistical reporting may have to follow a different path and implementation strategy than in the past.

Once the concepts, terminology, and categories have been developed by professional committees and project research groups, they are usually reviewed in the field, and finally revised for publication. There is probably not much that can be done to shorten these timeconsuming editorial and review processes until computer conferencing is more widely available.

It has also been customary to rely upon the federal government to implement library statistical standards through the collection and summarization of data supplied by individual libraries. This process has resulted in protracted delays in the publishing of results and in the modification of categories and terminology as described above. Further, the existing process of national reporting has been a separate, add-on function for most libraries, not yielding timely operational data that can be used for internal planning and control. That is, the data collected and ultimately reported in national summaries has not been skimmed efficiently off the top of a constantly updated database of detailed library measurements. Rather, it has been generated ad hoc, under pressure of external deadlines and constraints. The process has been additionally exacerbated by frequent organizational and personnel changes within the Office of Education (now Department of Education).

On the other hand, the bibliographic utilities are not subject to these forces, and the task of library data handling is central to their overall mission. Likewise, they have daily and direct operational involvement in individual libraries, which provides them with the information and motivation required to design and maintain an effective MIS. It is hoped that after the above handbook and standards have been published, the definitions and specifications for library statistics will be sufficiently explicit for the bibliographic utilities to begin to address the problem of implementation within a new subsystem of their current network-based catalog systems.

\section{IMPLEMENTATION}

The essential thesis of this paper is that what is now required to translate the studies and projects cited above into practical results is a complete, off-the-shelf MIS that a library administrator could purchase and install in any library. Like most generalized, commercial software and utility programs, such a system should be designed in a standardized and modular form, so that libraries of different types and sizes could select only those elements that suit their particular needs. If this is done on the basis of the conceptual model proposed earlier, it will be feasible for libraries to disregard data of certain types and at certain levels, and yet remain compatible within a system of broad regional and national coverage. Also, since the model has been thought through on the basis of the items and tasks shared by many individual libraries, the use of the MIS should assure enhanced planning, accountability, and operational control within each library.

When one thinks about the development of the OCLC system, beginning as it did with the early premise that each library should be able to select or maintain its own catalog card print format, the parallels with the needed MIS are recognized. If the statistical report formats are highly flexible, then each library can still devise reports that reflect its own particular needs. Since tables and graphs can be computer printed, there would be a saving in specialist skills and staff time at the individual library level. Like the catalog system on which it is modeled, the statistical data system would soon become so necessary and cost-effective that libraries would be unable to avoid the terminological standardization and uniform reporting that it will exact. By the same token, the provision of frequent, comprehensive, and up-to-date statistical reports will vastly enhance the decisionmaking and budget analysis capabilities of administrators at all levels.

What is proposed here is that the MIS be designed and installed as a subsystem of one of the existing network-based computer systems, such as OCLC, RLIN, or WLN. In terms of developmental difficulty, the system should present much less complexity than the cataloging subsystems already developed.

Two of the persistent problems in setting up and maintaining an MIS are (1) deciding who counts what and (2) assuring that the daily counts are fed on a scheduled basis to a central collection point. Counting goes on in most library departments, but in order to as- 
sure consistency and total coverage and to eliminate overlap, it is necessary to assign responsibility for specific data to appropriate departments and sections within the library. As an example, recently acquired microforms might be counted either in the acquisitions department (where they are received), the cataloging department (where they are processed), or the media department (where they are stored and serviced), but it is redundant and wasteful to have them counted in several departments as many libraries now do.

Input processing should be simplified on standardized, machine-readable reporting forms (mark-sense, optical scanning, etc.) that can be easily filled out at service desks and other points of activity. Forms can be collected and sent periodically for batch machine processing. Alternatively, data might be periodically keyed into a central computer through a general communications terminal.

Output reports should be highly flexible, allowing individual departmental as well as total library summaries on both a month-tomonth and annual basis. It should be possible in the institutional profile or system specification to delete or combine various counts, cross-tabulations, percentages, rankings, and other computations. Modular and flexible report formats and statistical computations are necessary in order to adapt to changing local and national reporting needs. Often, the prime reason that required statistical reports are not forthcoming is that there is insufficient staff to process or recombine the raw data already available but dispersed or inaccessible in various office files.

Each user would contract with the vendor for the level and amount of detailed processing and reporting required within the individual library. The specifications for processing of the data would be drawn up in a manner comparable with the OCLC profile now used to determine card format and other characteristics for each member library. Some available data cells could be left unspecified (distinctly not a possibility with the current LIBGIS forms) so that each library might assign some new measurement parameters that may be experimental, customized, or otherwise unique to its own particular operations, holdings, and services.

As with any computer system for the pro- cessing of library operational data, there will be a need for extensive documentation and training. Adapting the system to a given library's needs would be roughly analogous to the procedure now involved in writing an OCLC user profile. There will be a need for a comprehensive user manual explaining the system, terminology, and all procedures, with detailed examples. It will also be desirable to include practical guidance in the application of different sampling techniques to library data in the training sessions to be offered in subscriber libraries. While it is not feasible to collect certain types of activity and performance data on an ongoing basis, experience indicates that this is not required, since most library statistical activity measures tend to be very stable over time. Since fairly large samples are generally available, random or sampling errors are usually easy to avoid. ${ }^{19}$

\section{Future Research}

An expanded range and depth of library statistical data could be used for research purposes. We need data that can assist in constructing simulation models of individual libraries and distribution models of regional and national resources. Such data are required to plan a truly effective national library network. Generally, if librarians and researchers have been able to assemble the kinds of comprehensive data proposed here, it has been only episodically with significant summaries and interpretations limited to annual and usually less frequent reports.

For an example of the benefits that effective data and analysis can provide, one need only look to Baumol's fundamental work on library economics. ${ }^{20}$ This important study was based upon the Office of Education's $\mathrm{Li}$ brary Statistics of Colleges and Universities: Fall $1968,{ }^{21}$ and the annual statistical summaries of the Association of Research Libraries. The study is one of the most fundamental, empirically based analyses of library growth and cost trends available anywhere in the literature. Unfortunately, the data on which it was based was five years old at the time of publication, and there has been no comparable long-range interpretation of longitudinal data for libraries since 1968.

As regards the further elaboration of library data analysis based upon the use of the NCES Handbook, there are several topics on 
which future research is needed:

The basic areas which need additional work are: implementation of the suggested system in a wide variety of libraries; monitored testing of school and special library components; development of methods to measure the results of reserve sharing and networking; development of methods to record data on the agency roles of state and national libraries; and the development of adequate performance and outcome measures for all kinds of library services. ${ }^{22}$

A distinction about the availability and use of input versus output data seems appropriate here. Almost all historical data that has been assembled on academic libraries has been of the input nature, i.e., number of books held, dollars spent, staff available, etc. Increasingly, our funding authorities and accrediting agencies are asking for data on the educational outcomes of these costly resource investments. As enrollments drop and resources diminish, it becomes more important for administrators to provide evidence of the impact and results of expenditures. The MIS proposed here could, because of its flexibility and operational simplicity, make it feasible for many libraries to collect operational and performance data on an ongoing basis. By the same token, it is unlikely that this kind of data will ever be generated on a very wide scale if the procedures for processing the primary input data remain as they are now: rudimentary and inefficient.

We now have the operational capability of constructing comprehensive statistical summaries for libraries of all types. Once such a database has been assembled, it is interesting to speculate on the types of theoretical and policy studies that could then be pursued. One that fascinates this writer would be a study of branch units in academic libraries. Various configurations of academic libraries could be examined, while testing cost/benefit factors in highly centralized versus other more decentralized organizations. Given that this is one of the most resource intensive and poorly documented areas in academic library organization and management, the results could be quite interesting. ${ }^{23}$

REFERENCES

1. Philip M. Morse, Library Effectiveness: A Systems Approach (Cambridge, Mass.: M.I.T. Pr., 1968), p.5.

2. Edwin E. Olson, "Research in the Policy Process," in Irene Hoadley and Alice S. Clark, eds., Quantitative Methods in Librarianship: Standards Research, Management (Westport, Conn.: Greenwood Pr., 1972), p.102.

3. John A. Urquhart, and J. L. Schofield, "Measuring Readers' Failure at the Shelf," Journal of Documentation 7:273-86. (1971); in M. G., Beeler, and others, Measuring the Quality of Library Service: A Handbook, (Metuchen, N.J.: Scarecrow Pr., 1974), p.85-86.

4. American Library Association, Library Effectiveness: A State of the Art. An ALA Preconference sponsored by LAMA, LRRT, and RASD, Cochairmen: Neal K. Kaske and William Jones. (Chicago: The Association, 1980), 413 p.

5. Olson, "Research in the Policy Process," p.102.

6. Ralph Van Dusseldorp, "Some Principles for the Development of Management Information Systems," in Charles B. Johnson and William G. Katzenmeyer, eds., Management Information Systems in Higher Education: The State of the Art (Durham, N.C.: Duke Univ. Pr., 1969), p.33.

7. Eugene T. Neely, "Recent Developments in
Library Statistical Activities," Filomena Simora, ed., in The Bowker Annual of Library and Book Trade Information (New York: Bowker, 1980), p.368.

8. National Center for Educational Statistics, Handbook of Standard Terminology for Recording and Reporting Information about $\mathrm{Li}$ braries, in Mary Jo Lynch, ed., Library Data Collection Handbook: A Report Prepared for The National Center for Education Statistics (Chicago: American Library Assn., 1981), p.3.

9. F. W. Lancaster, The Measurement and Evaluation of Library Services (Washington, D.C.: Information Resources Pr., 1977).

10. Dennis Jones and others, Commentary to Library Statistical Data Base (Boulder, Colo.: National Center for Higher Education Management Systems, 1977), p.iii.

11. Robert S. Richard, The Numbers Game: Use and Abuse of Managerial Statistics (New York: McGraw-Hill, 1972), p.99-121.

12. Cyril W. Cleverdon, "Cranfield Tests on Index Language Devices," Aslib Proceedings 19:173-94 (June 1967).

13. Helen Tuttle, "TSCOR: The Technical Services Cost Ratio," Southeastern Librarian 19:15-25 (Spring 1969).

14. Michael S. Morton, Management Decision 
Systems: Computer-Based Support for Decision Making. (Boston: Harvard Univ. Graduate School of Business Administration, 1971).

15. J. Victor Baldridge and Michael L. Tierney, New Approaches to Management: Creating Practical Systems of Management Information and Management by Objectives (San Francisco: Jossey-Bass, 1979).

16. Kenneth E. Dowlin, “A Public Library Management System," in American Library Association, Library Effectiveness: A State of the Art (Chicago: American Library Assn., 1980), p.85-110.

17. James J. O'Brien, Management Information Systems: Concepts, Techniques and Applications (New York: Van Nostrand, 1970), p.11.

18. Katherine Emerson, "National Reporting on Reference Transactions, 1976-1978," $R Q$ 16:199-207 (Spring 1977).
19. Morris Hamburg, "Statistical Methods for Library Management," in Ching-Chih Chen, ed., Quantitative Measurement and Dynamic Library Service (Phoenix: Oryx Pr., 1978), p.38.

20. William J. Baumol and Marcus Matityahu, Economics of Academic Libraries (Washington, D.C.: American Council on Education, 1973).

21. Joel Williams, Library Statistics of Colleges and Universities (Data for Individual Institutions, Fall 1968) (Washington, D.C.: National Center for Educational Statistics, U.S. Office of Education, 1969).

22. National Center for Educational Statistics, Handbook of Standard Terminology, p.8.

23. Robert S. Runyon, "Power and Conflict in Academic Libraries," Journal of Academic Librarianship 3: p.202 (Sept. 1977).

APPENDix A

Decision Support System Summary Report*

\section{SERVICES}

\begin{tabular}{cccccc}
\cline { 3 - 3 } & & & (month) \\
$\begin{array}{c}\text { This month } \\
\text { this year }\end{array}$ & $\begin{array}{c}\text { This month } \\
\text { last year }\end{array}$ & $\begin{array}{c}\text { Y-T-D } \\
\text { this year }\end{array}$ & $\begin{array}{c}\text { Y-T-D } \\
\text { last year }\end{array}$ & $\begin{array}{c}\text { \% Change } \\
\text { monthly }\end{array}$ & $\begin{array}{c}\text { \% Change } \\
\text { Y-T }-\mathrm{D}\end{array}$
\end{tabular}

\section{Users}

Turnstyle count

Patrons registered (Faculty, students, staff, etc.)

Total target population (Faculty, students, staff, etc.)

$\%$ of target population registered

Active users ( $\%$ of population with charges by user group)

\section{Circulation}

Charges (Faculty, students, community users, etc.)

Reserves

Discharges

Holds

Recalls

Overdues (1st notice, $2 \mathrm{~d}$ notice, etc.)

Fines collected (\$)

Interlibrary loan (Loans, requests, etc.)

Items in circulation

Average charges per user to: (Faculty, students, staff, etc.)

Average loan duration

Average charge per patron fined

\footnotetext{
-The author is indebted to others for several ideas incorporated in this outline: Kenneth E. Dowlin, "A Public Library Management System," in American Library Association, Library Effectiveness: A State of the Art (Chicago: American Library Assn., 1980), p.85-110.; Robert D. Woodley, "A Performance Based Statistical Information System for the Library Services Division of the Merrill Library" (Utah State University, 1976).
} 


\section{SERVICES}

\section{Information and Instructional Services}

Questions answered (Directional, reference, research, etc.)

Tours and attendance

Classes offered and attendance

Bibliographies prepared

SDI notifications

Outside contacts

Database searches

Special Collections

User count

Reference and research questions

Materials paged

\section{FACILITIES}

\section{Space Utilization}

Shelving (linear feet)

-Expansion space available

-Additions:

Reference collection

General collection

Serials Collection

-\% utilization

Seating

- Total available

- Sample use counts

- \% utilization

Faculty studies

- Reservations

- Sample use counts

- \% utilization

\section{COLLECTIONS}

\section{Collections Growth}

Print Materials Added

Books - Volumes

Serials issues

U.S. documents

State and local documents

United Nations documents

Nonprint Materials Added

Microfilm rolls

Microfiche

Microcards

Cassettes

Audio

Video

Phono dises

Kits

Materials Withdrawn

Total Items Added to Collections 


\section{BUDGET}

Personal Services (\$)

Faculty

Library assistants

Part-time employees

Total savings

Departmental Allocations for Hourly Employees (\$)

Administration

Circulation

Collections development

Reference

Technical services

Acquisitions Expenditures (\$)

Books

Direct order (Faculty, library, etc.)

Approval plan

Standing order

Serials

Departmental allocations

(Anthropology, biology, . . . etc.)

Cost per item purchased

Dept. personal expenditures/items purchased 